\title{
Dialogue on Play
}

\author{
Kathryn Ricketts and Patrick Lewis
}

\section{The cover image of this special issue shares Lug - A playful research character \\ Performed by Dr. Kathryn Ricketts \\ Photo by Jenny Arnzten}

With a floor length overcoat, a large hat, and a bulky leather suitcase, my Beckettesque character of 13 years tells stories through a moving poetic narrative; a narrative that fragments meaning and blasts chronology and logic into space. The pieces fall where they may and are read differently by each of those who witness. Lug playfully traverses a narrative arc circuitously moving through and around points of arrival and points of departure evoking shared stories of belonging and displacement.

Kathryn: You know, Patrick, I have been improvising all of my dancing life, which is about 40 years now. I am always so grateful that my experience with this form has informed a beautiful balance between structure and impulse. Stephen Nachmanovitch (1990) refers to this as "the power of free play sloshing against the power of limits" (p. 33). I think this must be at the root of play. What do you think?

Patrick: I think Stephen is quite accurate in his characterization of play. However, I would add that the "power of limits" is in fact of our own construction. That is, I liken it to rough and tumble play in that the players are always attentive to each other's abilities, strengths, and limits, really watching each other's "play face" so as to be always pushing up against and expanding those limits, even when self-handicapping in that play in order to bring along the other players.

Kathryn: This reminds me of Davis and Sumara's (2006) notion of "enabling constraints" as a part of their complexity theory. Ramiah (2014), discussing their work, says that "enabling constraints are structural conditions that balance a need for a common identity or purpose, and sources of randomness that require the learning system to adapt" (p. 67). I think this randomness is actually the unfolding of ideas as the players move into disequilibrium. Part of the "rough and tumble" play that you write about is that idea of moving off axis and away from habituated postures of knowing. I think that the thrill of playing is the imminence that something new will emerge. As Davis and Sumara state, "complex emergence happens far from equilibrium" (p. 136).

Patrick: That's interesting and decidedly playful, don't you think? So, we might say instead of enabling constraints, we are playing with constraints? I don't want to go too far with this cognitive play for fear of doing what Vygotsky (1933/2002) warned of, that to "refuse to approach the problem of play from the standpoint of fulfilment of the child's needs, his (sic) incentives to act, and his ( sic) affective aspirations would result in a terrible intellectualization of play" (para. 7). Perhaps I am placing constraints on myself, ha ha! Of course, play is not simply the domain of childhood, I have to keep reminding myself of that. I agree with you, through play there is always the ever-present potential for something new to emerge from the play process, and that new thing can take a myriad of formshealing, understanding, insight, pleasure, and more!

Kathryn: This notion of the "terrible intellectualization of play" seems to be sliding down the Cartesian slope of binaries. Can we fully engage in play and still be thoughtful, mindful, and even smart? Well, I think yes ... can we be fully engaged with play and still have a purpose? Would having a purpose to "play" (healing or therapy, for example) rule out the tenets of play as allowing serendipitous discoveries? Would we then be cornering ourselves 
into expectations that may sabotage the event of play completely?

Patrick: Hmm, yes, that is important to consider; however, humans still struggle to transcend binary thought. Even play is always juxtaposed with work as its opposite. Yet, the ancient Greeks felt the opposite of play was seriousness. But to mind that only feeds into my thought that play is serious. So how can that be an opposite? While I'm sliding down this slope, I might as well bring up Brian Sutton-Smith (2001) and this particular idea I find so terribly compelling, even though it is still prisoner to binary thinking. For him, the opposite of play is not work-it is depression (p. 198). Herein lies the magnificence of play, in that the opposite of depression is play! And play is easily recognized but so difficult to define because it is so many things. In fact, it could be anything if the play frame is brought to it. So, yes, I think you are on to something. Play does potentially lead to discoveries, and purposeful play can be fulfilling, but it is always possessed with a playfulness that may allow it to transcend that purpose.

Kathryn: I was at an elementary school today and I passed a 6-year-old boy who was speeding by in the hallway. He was wearing a red sweatshirt with big white letters across the front that read "Never Stop Playing." At the same time there was a girl in the hallway who had passed out from playing too hard in the gym (perhaps she had come to school without breakfast). Playing is a complicated concept. I was looking after a friend who was dying of AIDS and who would speak to me about his fears and discomforts through a family of stuffed monkeys. Each had their name and voice, and they were critical in the attention and care we provided. We precariously balanced the entire family of monkeys on his coffin as we walked him to the hearse. I now teach with the assistance of a collection of puppets and stuffed animals that allow me to channel critical and uncomfortable information through a playful voice. I found this poem that I thought was useful to think about. I thought it was time for a poem in this conversation.

\section{It Is When We Play}

It is when we play that we know

Who is angry

He keeps his face like excrement

And says nothing good

It is when we play that we know

Who is sick

She drones and wants to put

Her head on my chest

It is when we play that we know

Who are wicked

They make us cry aloud

And do not play at all

It is when we play that we know

Who are part of us

They smile like we do

And sing like we always do.

Samuel Nze

Patrick: A poem-is a poem a play with words, or playing with words? "It is when we play that we know/Who are part of us." I wonder: Does this speak to the notion that play has receded so far into the background of our consciousness that we don't even notice it anymore-it's just there? When in fact play is a fundamental drive 
similar to sleep, and without enacting it, there are significant consequences. Perhaps we have been at play since humans emerged and what we are in fact playing toward across generations is to become human-we are playing at being human. Certainly, the articles in this collection suggest the myriad ways we can frame play and how humans pursue play. Perhaps it is time for us to set aside our playful explorations of play and share the pieces of this special issue with our readers.

Kathryn: I have been skipping, jumping, and sliding through this collection of scholarly works, and I feel so much awe for the ways in which these authors have embraced play in their individual scholarship. The breadth and scope of these inquiries has surprised me and quickened my own curiosity with the ways in which I define play in my scholarship. I am deeply grateful for this evocation and will follow all of these authors as they play(fully) move forward in their work.

\section{References}

Davis, B., \& Sumara, D. (2006). Complexity and education: Inquiries into learning, teaching, and research. Mahwah, NJ: Lawrence Erlbaum.

Nachmanovitch, S. (1990). Free play, improvisation in life and art. New York, NY: Penguin Putnam.

Ramiah, R. (2014). Complexity thinking in ALL practice. Journal of Academic Language and Learning, 8(3), A62-A71.

Sutton-Smith, B. (2001). The ambiguity of play. Cambridge, MA: Harvard University Press.

Vygotsky, L. (2002). Play and its role in the mental development of the child (C. Mulholland, Trans.). Psychology and Marxism Internet Archive 2002. Original work published 1933. Retrieved from: http://www.marxists.org/archive/vygotsky/works/1933/play.htm 